OPEN ACCESS

Edited by:

MariaFelice Marina Ghilardi, City University of New York,

United States

Reviewed by:

Linard Filli,

Balgrist University

Hospital, Switzerland

Francesco Asci,

Sapienza University of Rome, Italy

${ }^{*}$ Correspondence: Rocco Salvatore Calabrò salbro77@tiscali.it

TORCID:

Rocco Salvatore Calabrò orcid.org/0000-0002-8566-3166

Specialty section: This article was submitted to

Movement Disorders,

a section of the journa

Frontiers in Neurology

Received: 17 March 2020

Accepted: 25 June 2020

Published: 04 August 2020

Citation:

Naro A, Pignolo L, Sorbera C, Latella D, Billeri L, Manuli A, Portaro S,

Bruschetta D and Calabrò RS (2020)

A Case-Controlled Pilot Study on

Rhythmic Auditory

Stimulation-Assisted Gait Training and

Conventional Physiotherapy in

Patients With Parkinson's Disease

Submitted to Deep Brain Stimulation.

Front. Neurol. 11:794.

doi: 10.3389/fneur.2020.00794

\section{A Case-Controlled Pilot Study on Rhythmic Auditory Stimulation-Assisted Gait Training and Conventional Physiotherapy in Patients With Parkinson's Disease Submitted to Deep Brain Stimulation}

\author{
Antonino Naro ${ }^{1}$, Loris Pignolo ${ }^{2}$, Chiara Sorbera ${ }^{1}$, Desiree Latella ${ }^{1}$, Luana Billeri ${ }^{1}$, \\ Alfredo Manuli ${ }^{1}$, Simona Portaro ${ }^{1}$, Daniele Bruschetta ${ }^{3}$ and Rocco Salvatore Calabrò ${ }^{\text {1*t }}$ \\ ${ }^{1}$ IRCCS Centro Neurolesi Bonino Pulejo - Piemonte, Messina, Italy, ${ }^{2}$ S. Anna Institute, Research in Advanced \\ Neurorehabilitation (RAN), Crotone, Italy, ${ }^{3}$ Department of Biomedical, Dental Sciences and Morphological and Functional \\ Images, University of Messina, Messina, Italy
}

Deep brain stimulation (DBS) is indicated when motor disturbances in patients with idiopathic Parkinson's disease (PD) are refractory to current treatment options and significantly impair quality of life. However, post-DBS rehabilitation is essential, with particular regard to gait. Rhythmic auditory stimulation (RAS)-assisted treadmill gait rehabilitation within conventional physiotherapy program plays a major role in gait recovery. We explored the effects of a monthly RAS-assisted treadmill training within a conventional physiotherapy program on gait performance and gait-related EEG dynamics (while walking on the RAS-aided treadmill) in PD patients with $(n=10)$ and without DBS ( $n$ $=10)$. Patients with DBS achieved superior results than those without DBS concerning gait velocity, overall motor performance, and the timed velocity and self-confidence in balance, sit-to-stand (and vice versa) and walking, whereas both groups improved in dynamic and static balance, overall cognitive performance, and the fear of falling. The difference in motor outcomes between the two groups was paralleled by a stronger remodulation of gait cycle-related beta oscillations in patients with DBS as compared to those without DBS. Our work suggests that RAS-assisted gait training plus conventional physiotherapy is a useful strategy to improve gait performance in PD patients with and without DBS. Interestingly, patients with DBS may benefit more from this approach owing to a more focused and dynamic re-configuration of sensorimotor network beta oscillations related to gait secondary to the association between RAS-treadmill, conventional physiotherapy, and DBS. Actually, the coupling of these approaches may help restoring a residually altered beta-band response profile despite DBS intervention, thus better tailoring the gait rehabilitation of these PD patients.

Keywords: beta oscillations, deep brain stimulation (DBS), idiopathic Parkinson's disease (iPD), rhythmic auditory stimulation (RAS), treadmill gait training 


\section{INTRODUCTION}

Deep brain stimulation (DBS) consists in the surgical implantation of needle electrodes, connected to an implantable pulse generator, in specific targets of the brain in order to manage, among other, tremor, slowness, stiffness, and walking problems caused by idiopathic Parkinson's disease (iPD) (1). DBS is particularly indicated when drug response deteriorates, the OFF periods worsen, the patient develops intolerable medication-induced dyskinesias with refractory motor fluctuations or tremor, there is not a significant improvement with regard to dopaminergic medication $(<30 \%)$, and only modest improvement are appreciable during $\mathrm{ON}-$ state. DBS is contraindicated in patients over 75 years, with severe/malignant comorbidity considerably reducing life expectancy, chronic immunosuppression, distinct brain atrophy, and severe psychiatric disorder $(2,3)$.

A successful DBS allows patients to reduce their medications and improve their quality of life, given that it typically improves tremor, rigidity, bradykinesia, and levodopa-related motor complications $(4,5)$. Furthermore, DBS has some positive effect on gait velocity, stride length, and limbs range of movements $(4,6-8)$, but the overall effects on gait performance remain to be largely ascertained yet (9). Therefore, the rehabilitation plays a significant role to maintain and even potentiate motor outcomes, to counterbalance any functional impairment caused by or associated with DBS, and to adjust further DBS and medication for the rehabilitation therapy (10-12).

Conventional physical therapy and treadmill-assisted gait training provide patients with PD with great improvements in balance and gait stability and velocity (13-16). However, a few studies have assessed gait in PD patients who underwent DBS, reporting some promising results $(4,5,9,10)$. Integrating treadmill-assisted gait training equipped with rhythmic auditory stimulation (RAS) with physiotherapy has been shown to increase further speed, cadence, stride length, gait symmetry and stability in PD patients, because RAS works as a peripheral timekeeper (17-19). However, patients with DBS have not been assessed specifically for physiotherapy plus RAS-treadmill gait training aftereffects yet $(14,20,21)$. Furthermore, the possible interactions between physiotherapy plus RAS-treadmill and DBS aftereffects on the neural oscillations related to gait cycle have not been investigated so far. Given that physiotherapy, RAStreadmill, and DBS largely affects the pathological beta band activity in the corticothalamic-basal ganglia network $(20,22)$, a possible functional correlation between their effects on beta oscillations and gait could be hypothesized and potentially harnessed to maximize functional outcome recovery in patients with PD. Actually, physiotherapy plus RAS-treadmill could reveal and potentially restore a residually altered beta-band response profile despite DBS intervention. The prominent involvement of beta oscillatory activity is not surprising, as this is in keeping with its role in motor control and $\mathrm{PD}$ pathophysiology. Actually, beta regulation is a feature of motor control (including high levels during tonic contractions and low levels during dynamic voluntary movement) throughout the central nervous system and motor units $(23,24)$, and beta oscillations are increased in the basal ganglia and cortex in PD patients, being considered as a marker of the parkinsonian state (25-28).

To the best of our knowledge, no study evaluated such a putative functional correlation in a rehab perspective hitherto. Our study was aimed at assessing the motor and cognitive aftereffects of RAS-assisted treadmill training within a conventional rehabilitation program in PD patients with and without DBS. Furthermore, we proved whether DBS may interact with RAS-treadmill and physiotherapy according to scalp EEG data. In this regard, we explored the differences in EEG signatures between PD patients with and without DBS provided with an intensive, conventional and RAS-assisted treadmill gait training. This information may be useful to plan larger studies aimed at better tailoring gait rehabilitation in these PD patients.

\section{MATERIALS AND METHODS}

\section{Study Population}

In this pilot study, we consecutively screened all patients with a diagnosis of iPD who were hospitalized at our Institute between January and December 2019 for intensive rehabilitation training. Patients had to be bilateral subthalamic nucleus (STN) DBS user from at least 12 months prior to study inclusion (namely, DBS group), scored between 2 and 3 at the HoehnYahr modified scale (H\&Y) (being able to walk at least 10 meters without assistance), and scored at least 25 on the Mini Mental State Examination (MMSE). Furthermore, they had to be stable concerning medications dose with DBS, and without adequate response to treatment and with complications related to prolonged use of levodopa prior to DBS surgery. Patients who underwent treadmill training and/or other particular physiotherapy interventions in the previous 6 months, with other neurological, orthopedic, severe visual and auditory disorders, and taking other drugs acting on the central nervous system or modulating EEG dynamics than anti-parkinsonian drugs were excluded from the study. Fifteen patients matched the inclusion criteria, but only 10 were included in the study (three refused, two had problems with the DBS device). The enrolled patients were compared with a control group of $10 \mathrm{PD}$ individuals do not using DBS, matched for age, gender, disease duration, H\&Y stage, Levodopa equivalent daily dosage (LEDD), and MMSE (non-DBS group). Given the exploratory nature of the present study, the main aim of which was to provide evidence that could allow planning of a further confirmatory study, we focused on the efficacy of the training on gait performance. Therefore, the sample size was determined without any a priori formal statistical hypothesis. Clinical-demographic characteristics are detailed in Table 1. The local Ethics committee approved the study and each patient gave his/her written informed consent to study participation and data publication.

\section{Gait Training}

Patients underwent a RAS-assisted treadmill training within a conventional rehabilitation program. Patients practiced one session of RAS-assisted treadmill training and one session of 
TABLE 1 | Clinical demographic data.

\begin{tabular}{|c|c|c|c|c|c|c|c|c|c|c|c|c|c|c|c|c|c|c|c|c|c|c|c|c|c|}
\hline & \multirow[t]{2}{*}{ Gender } & \multirow{2}{*}{$\begin{array}{l}\text { Age } \\
\text { (yy) }\end{array}$} & \multirow[t]{2}{*}{ dd (yy) } & \multirow{2}{*}{$\begin{array}{l}\text { H\&Y } \\
\text { stage }\end{array}$} & \multirow{2}{*}{$\begin{array}{l}\text { LEDD } \\
\mathrm{mg} / \mathrm{day}\end{array}$} & \multirow[t]{2}{*}{ MMSE } & \multicolumn{5}{|c|}{ DBS setup (left/right electrode) } & \multicolumn{2}{|c|}{ UPDRS-OFF } & \multicolumn{2}{|c|}{ UPDRS-ON } & \multicolumn{2}{|c|}{ TUG (s) } & \multicolumn{2}{|c|}{$10 \mathrm{MWT}(\mathrm{m} / \mathrm{s})$} & \multicolumn{2}{|c|}{ BBS } & \multicolumn{2}{|c|}{ FES } & \multicolumn{2}{|c|}{ ACE-R } \\
\hline & & & & & & & $\begin{array}{l}\text { Implantation } \\
(\mathrm{mm})\end{array}$ & $\begin{array}{l}\text { Stimulation } \\
\text { frequency } \\
(\mathrm{Hz})\end{array}$ & $\begin{array}{c}\text { Active } \\
\text { contacts }\end{array}$ & $\begin{array}{l}\text { Impulse } \\
\text { amplitude } \\
\text { (V) }\end{array}$ & $\begin{array}{l}\text { Impulse } \\
\text { width } \\
(\mu \mathrm{s})\end{array}$ & e Pre & Post & Pre & Post & Pre & Post & Pre & Post & Pre & Post & Pre & Post & Pre & Pre \\
\hline \multirow{11}{*}{$\begin{array}{l}\text { DBS } \\
(n=10)\end{array}$} & M & 57 & 16 & 2.5 & 900 & 25 & 36 & $200 / 200$ & $1-0 / 6-7-$ & $3.6 / 3$ & $60 / 60$ & 20 & 11 & 11 & 9 & 11 & 9 & 0.8 & 1 & 39 & 54 & 54 & 51 & 79 & 91 \\
\hline & $\mathrm{F}$ & 67 & 14 & 3 & 700 & 27 & 14 & $240 / 240$ & $\begin{array}{l}1-3-1 \\
5-7-\end{array}$ & $1.9 / 2.2$ & $120 / 120$ & b 22 & 14 & 14 & 10 & 25 & 6 & 1 & 1.5 & 37 & 53 & 46 & 35 & 83 & 88 \\
\hline & M & 64 & 17 & 2.5 & 750 & 26 & 22 & $200 / 200$ & $\begin{array}{l}2+0 / \\
4-7-\end{array}$ & $2.3 / 2$ & $60 / 60$ & 35 & 17 & 17 & 11 & 10 & 6 & 1.1 & 1.4 & 37 & 51 & 40 & 32 & 84 & 93 \\
\hline & M & 56 & 16 & 3 & 750 & 26 & 18 & $200 / 200$ & $\begin{array}{l}3-1 \\
7-\end{array}$ & $3.6 / 3.2$ & $60 / 60$ & 48 & 24 & 24 & 19 & 16 & 7 & 1 & 1.4 & 50 & 54 & 34 & 28 & 80 & 85 \\
\hline & $\mathrm{F}$ & 58 & 15 & 3 & 650 & 27 & 17 & $210 / 210$ & $\begin{array}{l}1-2-1 \\
4-6-\end{array}$ & $2 / 2.5$ & $60 / 60$ & 47 & 32 & 42 & 16 & 17 & 13 & 1 & 1.5 & 42 & 49 & 27 & 21 & 80 & 87 \\
\hline & $\mathrm{F}$ & 66 & 17 & 3 & 600 & 26 & 24 & $200 / 200$ & $\begin{array}{l}3-2-1 \\
6-7-\end{array}$ & $3.1 / 3.6$ & $60 / 60$ & 28 & 14 & 14 & 10 & 16 & 12 & 1.3 & 1.4 & 41 & 44 & 34 & 20 & 83 & 83 \\
\hline & M & 66 & 10 & 2.5 & 700 & 27 & 22 & $130 / 130$ & $\begin{array}{c}1+/ \\
5-\end{array}$ & 3.6/3.2 & $60 / 60$ & 26 & 12 & 12 & 9 & 20 & 13 & 1.3 & 1.5 & 42 & 43 & 27 & 27 & 79 & 88 \\
\hline & $\mathrm{F}$ & 66 & 18 & 2.5 & 900 & 25 & 16 & $240 / 240$ & $\begin{array}{l}2-0 / \\
6-7-\end{array}$ & $2.8 / 3$ & $60 / 90$ & 32 & 18 & 18 & 10 & 12 & 9 & 0.9 & 1.2 & 50 & 52 & 26 & 16 & 77 & 79 \\
\hline & M & 56 & 11 & 3 & 950 & 25 & 18 & $210 / 210$ & $\begin{array}{l}3-1-1 \\
4-5-\end{array}$ & $2.8 / 2.8$ & $60 / 60$ & 47 & 17 & 17 & 10 & 16 & 8 & 1.3 & 1.7 & 37 & 52 & 36 & 26 & 75 & 79 \\
\hline & M & 67 & 17 & 3 & 500 & 26 & 15 & $210 / 210$ & $\begin{array}{l}2-1-1 \\
4-7-\end{array}$ & $2.2 / 2.6$ & $60 / 60$ & 32 & 22 & 22 & 18 & 18 & 15 & 0.8 & 1.1 & 47 & 54 & 39 & 29 & 74 & 87 \\
\hline & $\begin{array}{l}6 \mathrm{M} \\
4 \mathrm{~F}\end{array}$ & $62 \pm 5$ & $15 \pm 2$ & $\begin{array}{c}3 \\
(2.5-3)\end{array}$ & $740 \pm 143$ & $\begin{array}{c}26 \\
(25-27)\end{array}$ & & & & & & $\begin{array}{c}32 \\
(27-44)\end{array}$ & $\begin{array}{c}17 \\
(14-21)\end{array}$ & $\begin{array}{c}17 \\
(14-21)\end{array}$ & $\begin{array}{c}10 \\
(10-15)\end{array}$ & $16 \pm 4$ & $10 \pm 3$ & $1 \pm 0.2$ & $1.4 \pm 0.2$ & $\begin{array}{c}42 \\
(38-46)\end{array}$ & $\begin{array}{c}52 \\
(50-54)\end{array}$ & $\begin{array}{c}35 \\
(29-40)\end{array}$ & $\begin{array}{c}28 \\
(22-31)\end{array}$ & $\begin{array}{c}80 \\
(77-82)\end{array}$ & $\begin{array}{c}87 \\
(83-88)\end{array}$ \\
\hline Within- & & & & & & & & & & & & & $<0.001$ & & 0.01 & & 0.003 & & $<0.001$ & & 0.002 & & $<0.001$ & & 0.001 \\
\hline
\end{tabular}

group

$\begin{array}{llllll}\text { Non-DBS F } & 65 & 11 & 2.5 & 350 & 27\end{array}$

$(n=10)$

$\begin{array}{llllll}M & 58 & 12 & 2.5 & 700 & 27\end{array}$

$\begin{array}{cccccc}\text { F } & 57 & 11 & 2.5 & 700 & 27 \\ \text { F } & 64 & 12 & 3 & 800 & 27\end{array}$

$\begin{array}{llllll}M & 65 & 15 & 2.5 & 750 & 25 \\ M & 65 & 13 & 3 & 700 & 27\end{array}$

$\begin{array}{cccccc}M & 65 & 13 & 3 & 700 & 27 \\ F & 67 & 15 & 2.5 & 900 & 27\end{array}$

$\begin{array}{lllcll}\mathrm{F} & 67 & 15 & 2.5 & 900 & 27 \\ \mathrm{M} & 64 & 16 & 2.5 & 675 & 25 \\ \mathrm{~F} & 58 & 14 & 3 & 750 & 27\end{array}$

$\begin{array}{cccccc}M & 60 & 17 & 2.5 & 700 & 27 \\ 5 & 62 \pm 4 & 14 \pm 2 & 2.5 & 703 \pm 141 & 27\end{array}$

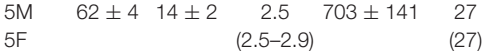

Within-

Wroup
group

difference

$\begin{array}{lllll}\text { Beseline } & 0.7 & 0.9 & 0.2 & 0.2\end{array}$

between-

group

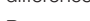

Pre-post

between-

group
difference

Mean values refer to mean $\pm s d$ or median (iqr). Post hoc $t$-test $p$-values are reported. Dd, disease duration. For left electrode, 0 was the most ventral contact and 3 was the most dorsal; for the right electrode, 4 was the most ventral contact and 7 the most dorsal.

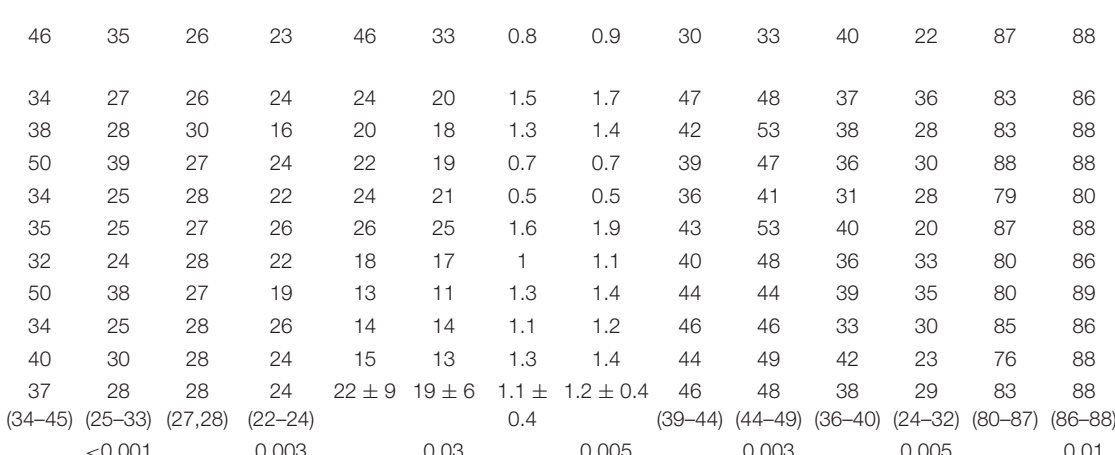$$
<0.001
$$

0.2

0.009

0.1

0.5

0.6

0.8

0.1

$<0.001$

0.02

0.001

$<0.001$

0.2

0.9

0.2 
conventional physiotherapy once a day, 6 days a week, for 1 month.

RAS-assisted treadmill training was conducted using the Gait Trainer 3 (GT3) (Biodex; Shirley, NY, US). GT3 is a validated electronic walkway equipped with an instrumented deck that monitors and records step length, step speed and step symmetry to train neurologic patients (including PD and stroke) in achieving better gait performance. By combining audio-visual feedback and music-assisted therapy, GT3 helps promoting neuroplasticity-based recovery processes $(18,29)$. The device provides clinicians with data on load distribution during the stance phase, the actual location of feet, and the matching of the length of the step performed with a pre-determined step length at a certain speed (audiomotor synchronization).

Each GT3 session lasted $30 \mathrm{~min}$, during which the patients were provided with simple, two-accent, metronome sounds (70 $\mathrm{dB}_{\mathrm{SPL}}$ ) to which they were instructed to synchronize the footsteps while walking. The bpm of the soundtrack (animals everywhere) was calculated considering patients' cadence measured at the beginning of the rehabilitation program at a comfortable gait speed (mean \pm sd $85 \pm 5 \mathrm{bpm}$, about $0.43 \mathrm{~m} / \mathrm{s}$ ) and was then increased of $5 \mathrm{bpm}$ every $3 \mathrm{~min}$ of walking up to $120 \mathrm{bpm}$ (about $0.61 \mathrm{~m} / \mathrm{s}$ ) or the maximum tolerable bpm. When the patients achieved the maximum tolerable or the target bpm, the $30 \mathrm{~min}$ session began. This procedure was repeated every day of treatment. We adopted the 120-bpm target frequency as it is intermediate between those potentially worsening step length and gait cadence, especially when too low (i.e., 60-90 bpm) or too high ( $>150 \mathrm{bpm})(30)$. The patients achieved the target bpm of 120 within the third-fourth session. The bpm value was kept if the patient was able to maintain step length symmetry safely; otherwise, the training was conducted using the same velocity as in the previous session. The interval between one beat/step and the subsequent one was kept constant in each session. The progression of intensity of training was individually adapted in order to prevent fatigue, for which patients were carefully monitored; in the case, walking speed was reduced to a comfortable pace (mean \pm sd $0.52 \pm$ $0.1 \mathrm{~m} / \mathrm{s}$ ). Furthermore, heart rate and pulse oximetry were monitored during each session. During the training, the patient was required to maintain step length symmetry as displayed on a screen put in front of the patient and to refrain from holding onto the handrails of the treadmill as much as possible.

Each session of conventional physiotherapy lasted $60 \mathrm{~min}$. It consisted of exercises aimed at targeting flexibility, balance, gait, and muscular tone and resistance $(31,32)$. Orthoticism and body alignment were monitored thoroughly.

The two session were separated by at least an hour of break. The order of session was random but counterbalanced within each patient and group. LEDD and DBS setup were kept constant during the monthly rehab training.

\section{Outcome Measures}

Patients were evaluated before and after training completion using the Unified Parkinson's disease rating scale (UPDRS) part
3 in OFF-dopa and ON-dopa, the Falls efficacy scale (FES), the Berg Balance Scale (BBS), the Timed Up\&Go test (TUG), the 10-meter walking test (10 MWT), and the Addenbrooke's Cognitive Examination-Revised (ACE-R). Furthermore, once the patient achieved his/her target bpm (third-fourth session), he/she was provided with EEG recording while walking on the RAS-treadmill. EEG was also recorded at the last day of the training.

\section{EEG Recording and Analysis}

EEG was recorded about 10 min after the patient started walking on the GT3, for $10 \mathrm{~min}$. All patients were in ON-state. The participant wore a standard 19-electrode headset wired to a Brain-Quick System (Micromed; Mogliano Veneto, Italy). Patients were prohibited from drinking coffee, smoking, and changing their bedtime during the 3 days prior to EEG recording. This was easily checked, as the participants were in-patients.

EEG was sampled at $512 \mathrm{~Hz}$, filtered at $1-45 \mathrm{~Hz}$, referenced to both the mastoids, and notch-filtered. Impedances were constantly monitored to be $<5 \mathrm{k} \Omega$. An electrooculogram (EOG) with a bipolar montage was also collected. Data were preprocessed using EEGLab. EEG recordings were first visually inspected to identify and remove data affected by prominent artifacts across all the recording channels. Then, the data decomposed into neural and artifactual components using the Infomax algorithm Independent Component Analysis (ICA) (33). It has been reported that employing ICA and linear autoregressive model easily allow identifying the periodical motion artifacts, as periodic was the walking activity in our study, present in the EEG recordings (34-36). Continuous data were then segmented into epochs starting from the left heel strike (HS) and ending at the next one to capture a complete stride. EEG segmentation was based on data synchronized from the important time points (left and right HS, left and right toe off-TO) furnished by the wireless G-Sensor inertial sensor (BTS Bioengineering; Milan, Italy) and used to extrapolate gait epochs. Thus, the single trial spectrograms were timewarped using a linear interpolation function, with the gait data used as milestones for realigning the EEG signals' time axes (i.e., aligning the time-points of the epochs for the left HS, right TO, and the next left HS, which were time-warped to 0,50 , and $100 \%$ of the gait cycle, respectively) $(34,35$, 37-39). Thus, left HS served as reference point in the gait cycle to which all segments were aligned. We thus obtained $356 \pm 32$ epochs after bad epoch removal (visual inspection and ICA).

We estimated the Event-Related Spectral Perturbation (ERSP) in relation to RAS provision in the alpha and beta frequency ranges (given that their spectral power changes are the most significantly occurring during treadmill walking) and in three regions of interest (ROI) related to motor control function (sensorimotor affordance, $\mathrm{P} 3 / 4$ and $\mathrm{T} 3 / 4$; motor execution, $\mathrm{C} 3 / 4, \mathrm{Cz}$, and $\mathrm{FCz}$; and motor planning, $\mathrm{F} 3 / 4, \mathrm{Fz}$, and $\mathrm{FCz}$ ), with visual region serving as a reference $(\mathrm{O} 1 / 2)(34,35,40)$. Overall, such ROIs are of particular relevance to interval timing, rhythm perception, and auditory-motor coordination 
(20,41-43). Specifically, we performed a time-frequency analysis (TFA) related to the phases of the gait cycle, so to assess changes in spectral measures within the gait cycle and between hemispheres (whether we found a ROI as significant) (44, 45). Thus, TFA was performed in $1 \mathrm{~Hz}$ step size on the entire frequency range using a "Hanning" taper, for each ROI (and side within the ROI). Using a sliding-window approach, the taper (length $100 \mathrm{~ms}$ ) was moved along the epochs in $5 \mathrm{~ms}$ steps. Such a taper setting is best for the assessed frequencies. Fourier transformations were performed on the single trials prior to averaging. The so-obtained power estimates were baseline corrected (we used the mean value across the whole epoch) for each frequency to obtain the relative signal change.

\section{Statistical Analysis}

Clinical changes were estimated by using Friedman or repeated measure ANOVA where appropriate, with the factor time (two levels: PRE and POST), and group (two levels: DBS and non-DBS). Bonferroni corrected post-hoc t-tests were carried out $(\alpha=0.05, p$-value $=0.05 / \mathrm{n}$ comparisons $)$. With regard to the EEG data analysis, ANOVA analysis was conducted with the factors time-window within the gait cycle (six levels: LTO $\frown 25 \%$ of gait cycle, $25 \%$ of gait cycle $\frown$ LHS, LHS $\frown$ RTO, RTO $\frown 75 \%$ of gait cycle, $75 \%$ of gait cycle $\frown$ RHS, and RHS $\frown$ LTO), group (two levels: DBS and non-DBS), ROI (four levels: visual, sensorimotor, motor execution, and motor planning), frequency-range (two levels: alpha and beta), and time (two levels: PRE and POST). The false discovery rate was controlled using the Benjamini-Hochberg procedure $(46,47)$. Statistical significance for main effects was set at 0.05 , and followed by post-hoc comparisons (with Fisher's LSD correction). Statistical analysis was conducted according to the intention-to-treat principle using multiple imputations to account for missing data (48). The personnel who conducted the statistical analysis was blinded to patient allocation.

\section{RESULTS}

\section{Baseline}

The DBS group consisted of 10 patients who were implanted with DBS about 1-3 years prior to study inclusion (Table 1). DBS setup (electrodes and Kinetra stimulators from Medtronic; Minneapolis, MN, USA) was characterized by a stimulation frequency of $130-240 \mathrm{~Hz}$, an impulse amplitude of $2.2-4.9 \mathrm{~V}$, and an impulse width of $60-120 \mu$ s (Table 1). The non-DBS group (control group) consisted of 10 patients matched for age, gender, disease duration, H\&Y stage, LEDD, and MMSE. There were not significant outcome differences at baseline between the groups (all $p>0.1$ ) but UPDRS-ON (Table 1). Clinically, all patients complained of mild to moderate disability and impaired postural reflexes ( $\mathrm{H} \& \mathrm{Y})$. Motor signs were mild-tomoderate in frequency and intensity, sufficient to affect, but not to prevent, a function (UPDRS). Patients were somewhat or fairly concerned about falling (FES), showed a mild-tomoderate impairment in performing static and dynamic activities (BBS and TUG), and complained of a very mild cognitive decline (ACE-R). Gait speed (10 MWT) was intermediate in the commonly reported range in $\mathrm{PD}$ patients, but it was however lower than the gait speed for healthy elderly (around the 60th centile), consistently with the decrease in BBS and increase in TUG.

The TFA disclosed significant and sharp intra-stride changes in spectral power and a clear distinction between alpha and beta power modulation in the DBS group. Specifically, we found a beta power increase and alpha power decrease within the left/right sensorimotor and the left/right motor execution ROIs and an alpha/beta power decrease in the left/right motor planning ROI in the $[25 \%$ of gait cycle $\frown$ LHS $\frown \mathrm{RTO} \frown 75 \%$ of gait cycle] time-window, with particular regard to the end of each stance phase (i.e., when the leading foot was in HS and the trailing foot was in TO) (Figure 1). Therefore, we found that power changes occurred in the sensorimotor, motor execution, and motor planning areas more for the contralateral TO/ipsilateral HS than for the ipsilateral TO/contralateral HS. Consequently, there were no significant left/right ROI differences in the overall sequencing of strides, as each activation phase was counterbalanced between the hemispheres within each, single phase of the gait cycle.

Conversely, we found a single response in the non-DBS group, i.e., an alpha and, even more, beta power increase in the $[25 \%$ of gait cycle $\frown$ LHS $\frown \mathrm{RTO} \frown 75 \%$ of gait cycle] time-window within each area but the visual one, which was followed by a short beta power decrease only within motor planning ROI (Figure 1). Left/right ROI activations were overall counterbalanced in the sequencing of strides within each, single phase of the gait cycle.

\section{Post-training}

All enrolled patients completed the monthly rehab session, without any adverse event. After the training, the DBS group improved more than non-DBS group did in: (i) 10 MWT, where DBS patients achieved a greater substantial meaningful change (at least $0.1 \mathrm{~m} / \mathrm{s}$ ) than non-DBS patients did (time $\times$ group $F=18, p=0.005, \eta^{2}=0.658$; DBS group $F=28, p<$ $0.001, \eta^{2}=0.847$; non-DBS group $\mathrm{F}=25, p<0.001, \eta^{2}=$ 0.833 ); (ii) TUG, which improved above the minimal detectable (MDC) change only in the DBS group (time $\times$ group $\mathrm{F}=$ $15, p=0.001, \eta^{2}=0.625$; DBS group $\mathrm{F}=22, p=0.001$, $\eta^{2}=0.818$; non-DBS group $\mathrm{F}=6.6, p=0.03, \eta^{2}=0.64$ ); and (iii) UPDRS-OFF, as DBS patients showed slight motor signs compared to non-DBS patients, who showed slight-to-mild motor signs $\left(\right.$ time $\times$ group $\mathrm{F}=25, p<0.001, \eta^{2}=0.714$; DBS group $\mathrm{F}=26, p<0.001, \eta^{2}=0.838$; non-DBS group $\mathrm{F}=$ 25, $\left.p<0.001, \eta^{2}=0.833\right)$. Post-hoc comparisons are reported in Table 1.

Conversely, both groups equally improved in BBS (both groups above the MDC; time $\times$ group $p=0.6$; DBS group $\mathrm{F}=$ $16, p=0.003, \eta^{2}=0.775$; non-DBS group $\mathrm{F}=18, p=0.002, \eta^{2}$ $=0.791$ ), FES (both groups from moderate to low concern about 


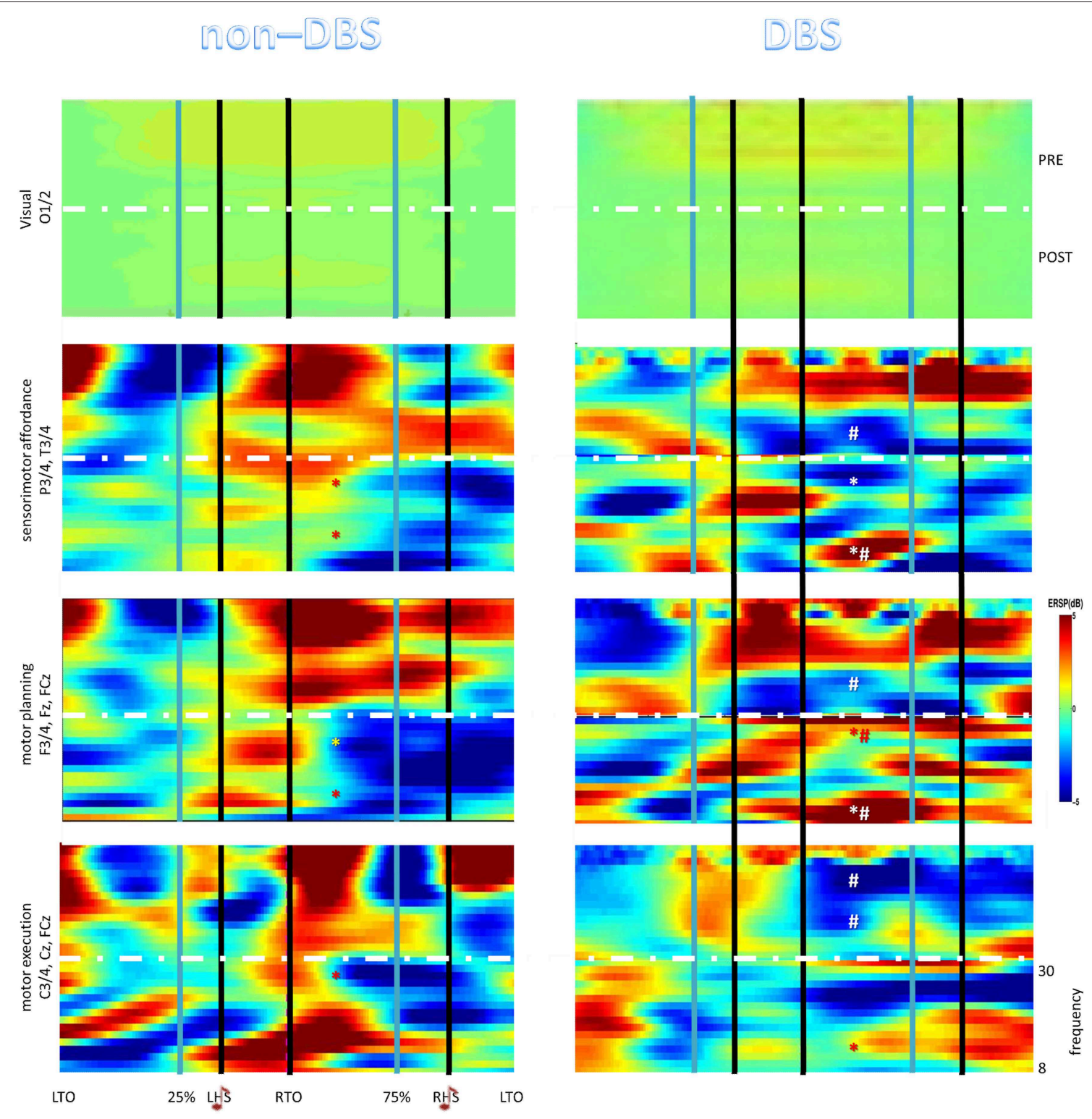

FIGURE 1 | The Event-Related Spectral Perturbation (ERSP) plots relative to the full gait cycle showing the average changes in spectral power during the gait cycle for the different electrode groups (brain areas). The horizontal axis is the percentage of gait cycle (as we performed a time-warping analysis) referred to the heel strikes (HS) and the toe offs (TO). *denotes post-pre significant changes $(p<0.001)$, \#between-group post-pre significant differences $(p<0.001)$.

falls; time $\times$ group $p=0.9$; DBS group $\mathrm{F}=28, p<0.001, \eta^{2}=$ 0.847 ; non-DBS group $\mathrm{F}=14, p=0.005, \eta^{2}=0.756$ ), and ACE$\mathrm{R}\left(\right.$ time $\times$ group $p=0.2 ;$ DBS group $\mathrm{F}=23, p=0.001, \eta^{2}=$ 0.823 ; non-DBS group $\left.\mathrm{F}=10, p=0.01, \eta^{2}=0.705\right)$. Post hoc comparisons are reported in Table 1.

The EEG pattern was significantly modified after the training in both groups and frequency-ranges, but with specific differences concerning the time-windows within the gait cycle and the ROIs (Figure 1) $($ group $\times$ time $\times$ frequency-band $\times$ ROI $\times$ time-window interaction $\left.\mathrm{F}=3.5, p<0.001, \eta^{2}=0.999\right)$.

Specifically, the baseline ERSP pattern in the DBS group was replaced by an alpha and beta power decrease in the [25\% of gait cycle LHS RTO 75\%] time-window within the sensorimotor and motor execution ROIs and by a beta decrease and alpha increase in the abovementioned time-window within the motor planning ROI (Figure 1). Power changes occurred in a ROI more for the contralateral TO/ipsilateral HS than for the ipsilateral $\mathrm{TO} /$ contralateral HS, as observed in the baseline recording. Consequently, there were no significant left/right ROI differences in the overall sequencing of strides.

The ERSP scenario was significantly different in the non-DBS group $($ group $\times$ time $\times$ frequency-band $\times R O I$ interaction $\mathrm{F}=$ 4.6, $p=0.004, \eta^{2}=0.899$ ), where the ERSP baseline pattern was replaced by a beta power decrease and an alpha power increase 


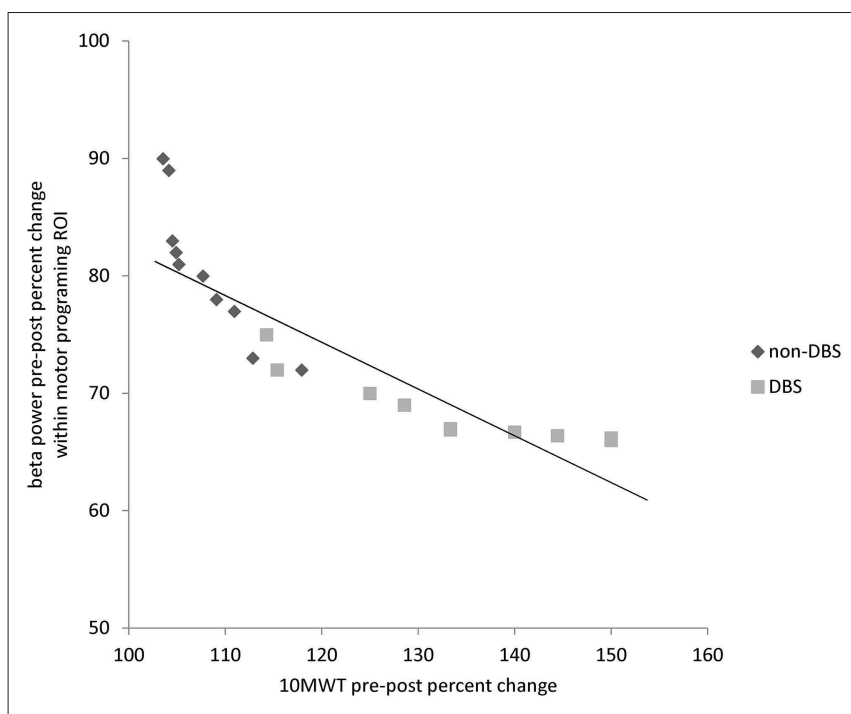

FIGURE 2 | Correlation plot between beta power pre-post percent changes within motor programming $\mathrm{ROI}$ and pre-post percent improvement in 10-meter walking test (10 MWT).

within each ROI in the abovementioned time-window (time $\times$ frequency-band interaction $\mathrm{F}=25, p<0.001, \eta^{2}=0.999$; time $\times R O I$ interaction $\left.\mathrm{F}=12, p<0.001, \eta^{2}=0.999\right)$ (Figure 1). Within- and between-group post-hoc comparisons were all $p<$ 0.001 (Figure 1).

With regard to clinical and electrophysiological correlations, we found a significant, negative correlation between beta power percent change (decrease) within motor programing ROI and 10 MWT percent change (increase) $(r=-0.772, p<0.001)$ (Figure 2).

\section{DISCUSSION}

To the best of our knowledge, this is the first time that patients with PD using DBS were provided with gait training with RAS-aided treadmill gait training in add-on to conventional training and were investigated for the dynamics of EEG responses in relation to the gait cycle to such treatment. Our work presents two main findings. First, RAS-assisted gait training plus conventional physiotherapy allowed the patients with DBS to achieve a greater improvement in gait velocity (as per 10 MWT score), overall motor performance (as per UPDR-III), and timed velocity and self-confidence in balance, sit-to-stand (and vice versa) and walking (as per TUG), as compared to patients without DBS. Furthermore, the coupled training enabled all patients to improve in the ability to safely balance during a series of predetermined tasks (dynamic and static balance) (as per BBS scores), the overall cognitive performance (including attention/orientation, memory, language, verbal fluency, and visuospatial skills; as per ACE-R), and the fear of falling (as per FES). Second, the main mechanism subtending the greater improvement in DBS patients compared to non-DBS ones may be due to the remodulation of the sensorimotor beta oscillations along the gait cycle induced by the functional association between physiotherapy plus RAS-treadmill and DBS.

\section{Clinical Aftereffects}

The clinical aftereffects our patients reported are consistent with previous data on the efficacy of RAS-assisted gait training plus conventional physiotherapy in improving gait performance in patients with $\operatorname{PD}(15,16,18,49)$. Actually, our rehab paradigm improved gait velocity, stability and overall mobility, and reduced the risk for falls and, thus, disability, in PD patients, in whom changes in gait often affect disability, morbidity, and mortality (50, 51). Specifically, patients achieved to walk faster, take longer strides, spend less time in stance and double support, and be affected by a lower gait variability and asymmetry and a less impaired postural control. All such findings are consistent with those coming from treadmill training (including gait speed, step length, stride variability, balance, and freezing) $(15,16,52-56)$.

The specific efficacy of treadmill-assisted gait training is likely to depend on the higher intensity, repeatability, and controllability of gait under treadmill gait therapy as compared to overground gait therapy. Noteworthy, all such issues are cardinal for an effective rehabilitation of gait in patients with $\operatorname{PD}(57,58)$. In detail, treadmill-assisted gait training provides patients with continuous sensory stimulation, external sensory cues, activation of gait central-pattern-generator circuits, visual feedback, and motor learning $(59,60)$. Furthermore, treadmill-assisted gait training ensures a safer and easier lower limb mobility, higher trunk control, larger range of movements of lower limbs joints, and a more controlled cardiorespiratory demand $(15,16)$.

All these effects were found in the DBS group using RAS. Therefore, treadmill-assisted gait training, coupled to RAS, could be helpful to maintain the clinical gait improvement after DBS surgery. Even though this issue deserves further studies $(14,20)$, we formerly found that RAS-assisted treadmill gait training was superior to stand-alone conventional treadmill gait training in improving motor performance in patients with $\mathrm{PD}$ (18). In the present study, patients with DBS showed gaitrelated functional gains, as those previously observed in patients without DBS. Furthermore, some specific, higher benefits in gait performance were appreciable in patients with DBS, as compared to those without DBS. Thus, our data extend the conventional physiotherapy and RAS-assisted gait training benefits to patients with DBS, who have not been assessed specifically for RASassisted gait training aftereffects yet $(14,20,21)$. Despite this is a case-controlled pilot study, the clinical aftereffects of conventional and RAS-assisted gait training are of importance, given that DBS has shown limited efficacy in gait abnormalities $(17,61)$, and that the motoric aftereffects of DBS require specific motor rehabilitation to maintain and improve the acquired functional gains (12).

The clinical benefits of conventional physiotherapy and RASassisted gait training are likely to depend on the intensity 
(every a day, six time a week, for 1 month) and sessionby-session repeatability of motor training. The RAS-assisted gait training as an add-on treatment ensured patients with precise rhythmicity of walking and high gait cycle repeatability within and along rehab sessions, which were also task-oriented (RAS-step synchronization and audio-motor feedback) $(18,49)$. Actually, all such issues are cardinal for an effective rehabilitation of gait in patients with $\mathrm{PD}(57,58)$.

One may argue that the great effects of treadmill walking and conventional physical therapy (excluding RAS effects) on the outcome measures was foreseeable, given that both patient groups were treated with an equal dosage of conventional and RAS-assisted gait training and were included in the study according to the absence of any physical therapy and treadmill walking in the 6 months prior to study onset. However, DBS patients showed some further positive effects as compared to non-DBS patients. This may depend on combined effects of DBS, physiotherapy and RAS-treadmill on neural oscillatory mechanisms related to gait cycle phases as suggested by the EEG data analyses.

\section{Putative Model of Interaction Between RAS-Plus-Physiotherapy and DBS}

The temporally predictable cues can support gait initiation and continuation both immediately and long after an extensive period of RAS by resetting the PD-related variability of sensorimotor timing skills $(19,55,62,63)$. In particular, RAS training improves patent's capacity to coordinate steps to the timing and rate of RAS, and to the time goal-directed movements to the beat onsets, with overall positive effects on gait performance (18). The exact neurophysiological underpinnings of RAS have to be elucidated clearly. Auditory-motor entrainment and the modulation of corticostriatal activity are considered the main mediators of the effects of the RAS (64). Specifically, RAS has been reported to favor the recovery of auditory-motor coupling mechanism within a large network (including both subcortical and cortical regions such as the cerebellum, supplementary motor area, and premotor cortex) in patients with PD (65-67). Auditory-motor coupling is important for internal timing and sensorimotor coordination mechanisms related to repetitive, semi-automated movements, including gait and upper limb pendolarity (49). These functions are impaired in patients with PD owing to an altered, dopamine-dependent, beta-band activity within basal ganglia-thalamo-cortical circuitry, with particular regard to STN and SMA, which are critical for externally-paced auditorymotor entrainment $(26,41,68,69)$. RAS has been show to be capable to remodulate such deteriorated beta band networking $(18,64,70,71)$, thus being the most important contributor to clinical improvement, similarly to what occurs using intensive gait training, levodopa and DBS (20, 60, 72, 73). Particularly, gait training has been shown to remodulate beta oscillations in a task-dependent manner, with consequential positive effects on gait stability, speed, and step length control, gait adaptation and anticipatory postural adjustments, visuomotor integration (71). With this regard, it could be that the beta band may subtend the temporal coordination of sensorimotor processes, and hence be involved in the temporal coordination of the HS during walking (74).

Actually, beta activity is hypersynchronized within basal ganglia-thalamo-cortical circuitry, resulting in an impairment of movements related to deficient timekeeping functions and dynamic scaling and sequencing of complex sensorimotor processes, including gait (26, 75-78). The correlation analyses in our work consistently support this issue, in that the beta modulation within frontal ROI was correlated with gait performance improvement significantly. Furthermore, it is worth noting that gait training acts on such deteriorated networks as well as levodopa and DBS do, improving audiomotor connectivity (79-81). Therefore, the hypothesis that physiotherapy plus RAS interacted with DBS synergistically by means of beta modulation, eventually improving gait performance seems reliable. In this regard, the synergy between RAS, physiotherapy and DBS is suggested by the specific post-treatment differences we found between DBS and non-DBS gait training outcomes concerning beta oscillations.

At baseline, DBS patients showed a better beta modulation pattern along the gait cycle, as compared to non-DBS patients. This regarded the frontal electrodes in particular, i.e., a beta power peak during the double support phase, which is in keeping with a feedback signaling of step synchronization correctness (82-84). Actually, the non-DBS patients showed a beta oscillatory activity increase externally to the double support and a lack of beta suppression during contralateral foot lift, which is in keeping with the detrimental beta oscillatory activity along the basal ganglia-thalamo-cortical circuitry in patients with PD $(23,50,60,71,72,85-90)$. This condition reflects the restriction of patients with PD into timing function-based motor tasks and the hastening phenomenon (i.e., the involuntarily acceleration of motion instead of precisely synchronizing with rhythmic external cues) (24, 91-93).

The baseline alpha and beta pattern was remodulated at the end of the training largely in both groups. However, specific between-group differences were appreciable. In particular, gait training in non-DBS patients favored a gait cycle phase specific, alpha and beta power modulation within each sensorimotor area, as per our previous findings (18). Therefore, RAS plus physiotherapy may have reshaped the intrinsic rhythmicity related to gait cycle, thus improving motor performance and positively affecting bradykinesia, which is properly related to beta modulation $(23,26,71,72,85,87,94)$. However, such a beta oscillation modulation has been also reported during walking, cycling, stepping training and, noteworthy, DBS and levodopa treatment $(20,60,71-74,86,90)$. On the other hand, the association between DBS and RAS plus physiotherapy may have allowed a greater focusing on beta frequencies, mainly in the double stance phase and within sensorimotor and frontal electrodes, in keeping with the beta desynchronization during movement execution followed by a beta rebound between two consecutive rhythmic movements $(95,96)$. In other words, DBS could have focused and boosted RAS plus physiotherapy aftereffects mainly acting on the feedback signaling of step synchronization correctness during the gait training (as indicated 
by the modulation of beta activity during the double stance phase) within parts of the wide auditory-motor coordination network entrained by RAS (including SMA and STN) and of the sensorimotor network entrained by gait practice on the treadmill itself (including motor and premotor cortices, primary sensorimotor cortex, and dorsal anterior cingulate cortex) (97). This coupled effect between RAS plus physiotherapy and DBS is suggested by the significant beta modulation we found within the frontal (motor program) ROI, that includes SMA, which is highly connected with STN and is critical for beta-band based internal synchronization mechanisms, including gait (26, $41,41,42,68,69,98,99)$. In this regard, the application of transcranial magnetic stimulation over the SMA has been shown to transiently reduce beta oscillations in the STN as measured with DBS electrodes (100). Furthermore, the focusing of beta activity modulation in this part of the gait cycle and in SMA electrodes suggest an error correction in the next temporal parameters of step cycles, i.e., a retrospective evaluation of gait performance so as to update and improve the subsequent gait performance (84).

All the above mentioned issues suggest that the oscillatory effects we observed are likely to depend on the improvement of the basal ganglia-thalamo-cortical circuitry induced by the synergy between RAS plus physiotherapy and DBS. The former activates gait-related sensorimotor and auditory-motor coordination network at cortical level (through basal gangliathalamo-cortical circuitry that plays a critical role in modulating beta band activity during synchronization tasks (i.e., RAS treadmill) $(42,43,93,97,98,101,102)$. The association between audiomotor synchronization and the amount of sensorimotor information related to gait execution, together with DBS stimulation, may modulate beta oscillations within basal ganglia-thalamo-cortical circuits that contribute to long-term potentiation(LTP)-like and spike-timing dependent plasticity mechanisms at the cortical level (maybe through GABAergic and cholinergic neural transmission) (103-111). Actually, we can hypothesize that DBS and RAS plus physiotherapy may interact through a sort of associative plasticity, which is already triggered by the coupling of RAS with steps during gait training $(18,49)$, thus further suggesting that there may be a synergy among DBS, RAS, and physiotherapy. Indeed, the repeated stimulation of basal ganglia-thalamo-cortical loop by part of DBS and RAS plus physiotherapy may have led to a LTPlike plasticity potentiation in the motor cortex, of which beta modulation is a feature $(112,113)$. Overall, the issues we described suggest that the reported EEG activities likely represent a true synchronization of three interacting oscillators, i.e., DBS, RAS, and physiotherapy, with significant consequences on betafrequency based cortical excitability.

\section{Limitations}

There are some limitations to acknowledge. First, the small sample enrolled and the relatively high standard deviation values in some post-treatment measures may have limited the significance of some outcome measure changes. However, this was a pilot, case-control study aimed at preliminary assessing the effectiveness of RAS training in patients with PD using DBS.

Second, there was not a control experimental group of PD patients undergoing treadmill-based rehabilitation without RAS. However, we have formerly shown that treadmill-based rehabilitation without RAS provides patients with inferior gait outcomes than treadmill-based rehabilitation with RAS (18). Nonetheless, further clinical trials on patients who did not practice RAS, practiced different RAS frequencies, or withdrew DBS, are necessary to confirm our promising findings $(114,115)$.

Third, one may be concerned on the fact that surface EEG recordings from the frontal ROIs do not selectively detect the oscillatory activity of the STN and SMA, which are known to be crucial for the externally-paced auditory-motor entrainment. However, it has been reported that the neural dynamics among STN, SMA, premotor cortices (midline electrodes) and prefrontal cortices (frontal electrodes) can be deduced by surface EEG (116-120). Nonetheless, a key confirmation would arise from the recording of surface EEG using higher electrode density and of the oscillation dynamics in basal ganglia through DBS electrodes (bilateral STN) in PD patients during RAS-based training.

Fourth, there could be a concern on EEG recording while using DBS and on the frequency bands we analyzed, not including the gamma frequency range. Indeed, we did not find focally distorted spreads of EEG signals compatible with surgery-related skull defects or DBS stimulation. Even though gamma oscillatory activity is also relevant in patients with PD (for instance, the swing phase is accompanied by gamma power decrease in the contralateral central electrodes, beside a significant bilateral alpha-beta power decrease) $(117,121-123)$, gamma recording is easily affected by movement artifacts and may need specific equipment to reliably reported and discussed (18). However, this interesting aspect may be addressed in future, larger clinical trials.

Last, one may have expected a larger effect on UPDRS-III than the one we found. This is likely to depend on the fact that we enrolled patients with long-term carry-over effects of chronic, high-frequency DBS $(118,124-126)$.

\section{CONCLUSIONS}

Our work suggests that RAS-assisted gait training coupled to conventional physiotherapy is an effective tool to improve gait performance in patients with PD with and without DBS. Interestingly, patients with DBS achieved better results concerning gait velocity and stability. Specifically, patients with DBS may have benefited more from this approach compared to those without DBS owing to a more focused and dynamic reconfiguration of sensorimotor beta oscillations related to gait secondary to DBS effects on RAS gait training plus conventional physiotherapy. Potentiating DBS using RAS gait training plus conventional physiotherapy may help restoring a residually altered beta-band response profile despite DBS intervention, thus better tailoring the gait rehabilitation of PD patients submitted to DBS. 


\section{DATA AVAILABILITY STATEMENT}

The datasets generated for this study are available on request to the corresponding author.

\section{ETHICS STATEMENT}

The studies involving human participants were reviewed and approved by IRCCS Centro Neurolesi Bonino Pulejo. The

\section{REFERENCES}

1. Weaver FM, Follett K, Stern M, Hur K, Harris C, Marks WJ, et al. Bilateral deep brain stimulation vs best medical therapy for patients with advanced Parkinson disease: a randomized controlled trial. JAMA. (2009) 301:63-73. doi: 10.1001/jama.2008.929

2. Malek N. Deep brain stimulation in Parkinson's disease. Neurol India. (2019) 67:968-78. doi: 10.4103/0028-3886.266268

3. Groiss SJ, Wojtecki L, Südmeyer M, Schnitzler A. Deep brain stimulation in Parkinson's disease. Ther Adv Neurol Disord. (2009) 2:20-8. doi: 10.1177/1756285609339382

4. Johnsen EL, Mogensen PH, Sunde NA, Østergaard K. Improved asymmetry of gait in Parkinson's disease with DBS: gait and postural instability in Parkinson's disease treated with bilateral deep brain stimulation in the subthalamic nucleus. Mov Disord. (2009) 24:590-7. doi: 10.1002/mds.22419

5. Ferrarin M, Rizzone M, Bergamasco B, Lanotte M, Recalcati M, Pedotti A, et al. Effects of bilateral subthalamic stimulation on gait kinematics and kinetics in Parkinson's disease. Exp Brain Res. (2005) 160:517-27. doi: 10.1007/s00221-004-2036-5

6. St George RJ, Nutt JG, Burchiel KJ, Horak FB. A meta-regression of the longterm effects of deep brain stimulation on balance and gait in PD. Neurology. (2010) 75:1292-9. doi: 10.1212/WNL.0b013e3181f61329

7. St George RJ, Carlson-Kuhta P, Burchiel KJ, Hogarth P, Frank N, Horak FB. The effects of subthalamic and pallidal deep brain stimulation on postural responses in patients with Parkinson disease. J Neurosurg. (2012) 116:134756. doi: $10.3171 / 2012$.2.JNS11847

8. St George RJ, Carlson-Kuhta P, Nutt JG, Hogarth P, Burchiel KJ, Horak FB. The effect of deep brain stimulation randomized by site on balance in Parkinson's disease. Mov Disord. (2014) 29:949-53. doi: 10.1002/mds.25831

9. Sato K, Aita N, Hokari Y, Kitahara E, Tani M, Izawa N, et al. Balance and gait improvements of postoperative rehabilitation in patients with Parkinson's disease treated with Subthalamic Nucleus Deep Brain Stimulation (STNDBS). Parkinson's Dis. (2019) 2019:7104071. doi: 10.1155/2019/7104071

10. Tassorelli C, Buscone S, Sandrini G, Pacchetti C, Furnari A, Zangaglia R, et al. The role of rehabilitation in deep brain stimulation of the subthalamic nucleus for Parkinson's disease: a pilot study. Parkinsonism Relat Disord. (2009) 15:675-81. doi: 10.1016/j.parkreldis.2009.03.006

11. Allert N, Dohle C, Horn JW, Kelm S, Kirsch H, Nolte PN, et al. Rehabilitation of Parkinson's patients with deep brain stimulation. Exp Neurol Rehabil Center Godeshöhe Nervenarzt. (2011) 82:462-7. doi: 10.1007/s00115-010-3092-7

12. Vercruysse S, Vandenberghe W, Münks L, Nuttin B, Devos H, Nieuwboer A. Effects of deep brain stimulation of the subthalamic nucleus on freezing of gait in Parkinson's disease: a prospective controlled study. J Neurol Neurosurg Psychiatr. (2014) 85:871-7. doi: 10.1136/jnnp-2013-306336

13. Hidalgo-Agudo RD, Lucena-Anton D, Luque-Moreno C, Heredia-Rizo AM, Moral-Munoz JA. Additional physical interventions to conventional physical therapy in Parkinson's disease: a systematic review and metaanalysis of randomized clinical trials. J Clin Med. (2020) 9:1038. doi: $10.3390 / \mathrm{jcm} 9041038$

14. Luna N, Lucareli P, Sales VC, Speciali D, Alonso AC, Peterson MD, et al. Treadmill training in Parkinson's patients after deep brain patients/participants provided their written informed consent to participate in this study.

\section{AUTHOR CONTRIBUTIONS}

RC: conceptualization and reviewing and editing. AN and LP: methodology. AN and LB: investigation. CS, DL, LB, and AM: data curation. AN: original draft preparation. RC and DB: supervision. All authors contributed to the article and approved the submitted version. stimulation: effects on gait kinematic. NeuroRehabilitation. (2018) 42:14958. doi: 10.3233/NRE-172267

15. Miyai I, Fujimoto Y, Ueda Y, Yamamoto H, Nozaki S, Saito T, et al. Treadmill training with body weight support: its effect on Parkinson's disease. Arch Phys Med Rehabil. (2000) 81:849-52. doi: 10.1053/apmr.2000.4439

16. Miyai I, Fujimoto Y, Yamamoto H, Ueda Y, Saito T, Nozaki S, et al. Long-term effect of body weight-supported treadmill training in Parkinson's disease: a randomized controlled trial. Arch Phys Med Rehabil. (2002) 83:1370-3. doi: 10.1053/apmr.2002.34603

17. Bella SD, Benoit CE, Farrugia N, Schwartze M, Kotz SA. Effects of musically cued gait training in Parkinson's disease: beyond a motor benefit. Ann N Y Acad Sci. (2015) 1337:77-85. doi: 10.1111/nyas.12651

18. Calabrò RS, Naro A, Filoni S, Pullia M, Billeri L, Tomasello P, et al. Walking to your right music: a randomized controlled trial on the novel use of treadmill plus music in Parkinson's disease. J Neuroeng Rehabil. (2019) 16:68. doi: 10.1186/s12984-019-0533-9

19. Thaut MH, McIntosh GC, Rice RR, Miller RA, Rathbun J, Brault JM. Rhythmic auditory stimulation in gait training for Parkinson's disease patients. Mov Disord. (1996) 11:193-200. doi: 10.1002/mds.870110213

20. Gulberti A, Moll CK, Hamel W, Buhmann C, Koeppen JA, Boelmans $\mathrm{K}$, et al. Predictive timing functions of cortical beta oscillations are impaired in Parkinson's disease and influenced by L-DOPA and deep brain stimulation of the subthalamic nucleus. NeuroImage Clin. (2015) 9:436-49. doi: 10.1016/j.nicl.2015.09.013

21. Lopez WO, Higuera CA, Fonoff ET, Souza Cde O, Albicker U, Martinez JA. Listenmee and Listenmee smartphone application: synchronizing walking to rhythmic auditory cues to improve gait in Parkinson's disease. Hum Mov Sci. (2014) 37:147-56. doi: 10.1016/j.humov.2014.08.001

22. Müller EJ, Robinson PA. Suppression of Parkinsonian beta oscillations by deep brain stimulation: determination of effective protocols. Front Comput Neurosci. (2018) 12:98. doi: 10.3389/fncom.2018.00098

23. Brown P. Abnormal oscillatory synchronisation in the motor system leads to impaired movement. Curr Opin Neurobiol. (2007) 17:656-64. doi: 10.1016/j.conb.2007.12.001

24. Engel AK, Fries P. Beta-band oscillations - signalling the status quo? Curr Opin Neurobiol. (2010) 20:156-65. doi: 10.1016/j.conb.2010.02.015

25. Ramirez Pasos UE, Steigerwald F, Reich MM, Matthies C, Volkmann J, Reese R. Levodopa modulates functional connectivity in the upper beta band between subthalamic nucleus and muscle activity in tonic and phasic motor activity patterns in Parkinson's disease. Front Hum Neurosci. (2019) 13:223. doi: $10.3389 /$ fnhum. 2019.00223

26. Little S, Brown P. The functional role of beta oscillations in Parkinson's disease. Parkinsonism Relat Disord. (2014) 20(Suppl. 1):S44-8. doi: 10.1016/S1353-8020(13)70013-0

27. Nelson AB, Moisello C, Lin J, Panday P, Ricci S, Canessa A, et al. Beta oscillatory changes and retention of motor skills during practice in healthy subjects and in patients with Parkinson's disease. Front Hum Neurosci. (2017) 11:104. doi: 10.3389/fnhum.2017.00104

28. Moisello C, Blanco D, Lin J, Panday P, Kelly SP, Quartarone A, et al. Practice changes beta power at rest and its modulation during movement in healthy subjects but not in patients with Parkinson's disease. Brain Behav. (2015) 5:e00374. doi: 10.1002/brb3.374 
29. De Luca R, Latella D, Maggio MG, Leonardi S, Sorbera C, Di Lorenzo G, et al. Do patients with PD benefit from music assisted therapy plus treadmill-based gait training? An exploratory study focused on behavioral outcomes. Int J Neurosci. (2020) 1-8. doi: 10.1080/00207454.2019.1710147

30. Leow LA, Parrott T, Grahn JA. Individual differences in beat perception affect gait responses to low- and high-groove music. Front Hum Neurosci. (2014) 8:811. doi: 10.3389/fnhum.2014.00811

31. Cakit BD, Saracoglu M, Genc H, Erdem HR, Inan L. The effects of incremental speed-dependent treadmill training on postural instability and fear of falling in Parkinson's disease. Clin Rehabil. (2007) 21:698-705. doi: 10.1177/0269215507077269

32. Ashburn A, Fazakarley L, Ballinger C, Pickering R, McLellan LD, Fitton C. A randomised controlled trial of a home based exercise programme to reduce the risk of falling among people with Parkinson's disease. J Neurol Neurosurg Psychiatr. (2007) 78:678-84. doi: 10.1136/jnnp.2006.099333

33. Delorme A, Makeig S. EEGLAB: an open source toolbox for analysis of single-trial EEG dynamics including independent component analysis. $J$ Neurosci Methods. (2004) 134:9-21. doi: 10.1016/j.jneumeth.2003.10.009

34. Gwin JT, Gramann K, Makeig S, Ferris DP. Electrocortical activity is coupled to gait cycle phase during treadmill walking. Neuroimage. (2011) 54:1289-96. doi: 10.1016/j.neuroimage.2010.08.066

35. Presacco A, Goodman R, Forrester L, Contreras-Vidal JL. Neural decoding of treadmill walking from noninvasive electroencephalographic signals. $J$ Neurophysiol. (2011) 106:1875-87. doi: 10.1152/jn.00104.2011

36. Castermans T, Duvinage M, Cheron G, Dutoit T. EEG and Human Locomotion Descending Commands and Sensory Feedback Should Be Disentangled FromArtifacts Thanks to New Experimental Protocols Position Paper. In Proceedings of the International Conference on Bio-inspired Systems and Signal Processing, ALgarve. (2012). 1:309-14.

37. Pizzamiglio S, Abdalla H, Naeem U, Turner DL. Neural predictors of gait stability when walking freely in the real-world. J Neuroeng Rehabil. (2018) 15:11. doi: 10.1186/s12984-018-0357-z

38. Seeber M, Scherer R, Wagner J, Solis-Escalante T, Müller-Putz GR. EEG beta suppression and low gamma modulation are different elements of human upright walking. Front Hum Neurosci. (2014) 8:485. doi: 10.3389/fnhum.2014.00485

39. Seeber M, Scherer R, Wagner J, Solis-Escalante T, Müller-Putz GR. High and low gamma EEG oscillations in central sensorimotor areas are conversely modulated during the human gait cycle. Neuroimage. (2015) 112:318-26. doi: 10.1016/j.neuroimage.2015.03.045

40. Handojoseno A, Naik GR, Gilat M, Shine JM, Nguyen TN, Ly QT, et al. Prediction of freezing of gait in patients with Parkinson's disease using EEG signals. Stud Health Technol Inform. (2018) 246:124-31.

41. Fujioka T, Trainor LJ, Large EW, Ross B. Internalized timing of isochronous sounds is represented in neuromagnetic $\beta$ oscillations. J Neurosci. (2012) 32:1791-802. doi: 10.1523/JNEUROSCI.4107-11.2012

42. Grahn JA, Brett M. Rhythm and beat perception in motor areas of the brain. J Cogn Neurosci. (2007) 19:893-906. doi: 10.1162/jocn.2007.19.5.893

43. Rao SM, Harrington DL, Haaland KY, Bobholz JA, Cox RW, Binder JR. Distributed neural systems underlying the timing of movements. J Neurosci. (1997) 17:5528-35. doi: 10.1523/JNEUROSCI.17-14-05528.1997

44. Leocani L, Toro C, Manganotti P, Zhuang P, Hallett M. Event-related coherence and event-related desynchronization/synchronization in the $10 \mathrm{~Hz}$ and $20 \mathrm{~Hz}$ EEG during self-paced movements. Electroencephalogr Clin Neurophysiol. (1997) 104:199-206. doi: 10.1016/S0168-5597(96)96051-7

45. Senhadji L, Wendling F. Epileptic transient detection: wavelets and time-frequency approaches. Neurophysiol Clin. (2002) 32:175-92. doi: 10.1016/S0987-7053(02)00304-0

46. Benjamini Y, Hochberg Y. Controlling the false discovery rate: a practical and powerful approach to multiple testing. J R Stat Soc Ser B. (1995) 57:289-300. doi: 10.1111/j.2517-6161.1995.tb02031.x

47. Groppe DM, Urbach TP, Kutas M. Mass univariate analysis of event-related brain potentials/fields I: a critical tutorial review. Psychophysiology. (2011) 48:1711-25. doi: 10.1111/j.1469-8986.2011.01273.x

48. Jakobsen JC, Gluud C, Wetterslev J, Winkel P. When and how should multiple imputation be used for handling missing data in randomized clinical trials - a practical guide with flowcharts. BMC Med Res Methodol. (2017) 17:162. doi: 10.1186/s12874-017-0442-1
49. Ashoori A, Eagleman DM, Jankovic J. Effects of auditory rhythm and music on gait disturbances in Parkinson's disease. Front Neurol. (2015) 6:234. doi: 10.3389/fneur.2015.00234

50. Peterson DS, Horak FB. Neural Control of Walking in People with Parkinsonism. Physiology. (2016) 31:95-107. doi: 10.1152/physiol.00034.2015

51. Kalia LV, Lang AE. Parkinson's disease. Lancet. (2015) 386:896-912. doi: 10.1016/S0140-6736(14)61393-3

52. Toole T, Maitland CG, Warren E, Hubmann MF, Panton L. The effects of loading and unloading treadmill walking on balance, gait, fall risk, and daily function in Parkinsonism. NeuroRehabilitation. (2005) 20:307-22. doi: 10.3233/NRE-2005-20406

53. Herman T, Giladi N, Gruendlinger L, Hausdorff JM. Six weeks of intensive treadmill training improves gait and quality of life in patients with Parkinson's disease: a pilot study. Arch Phys Med Rehabil. (2007) 88:1154-8. doi: 10.1016/j.apmr.2007.05.015

54. Fisher BE, Wu AD, Salem GJ, Song J, Lin CH, Yip J, et al. The effect of exercise training in improving motor performance and corticomotor excitability in people with early Parkinson's disease. Archives Phys Med Rehabil. (2008) 89:1221-9. doi: 10.1016/j.apmr.2008.01.013

55. Frazzitta G, Maestri R, Uccellini D, Bertotti G, Abelli P. Rehabilitation treatment of gait in patients with Parkinson's disease with freezing: a comparison between two physical therapy protocols using visual and auditory cues with or without treadmill training. Mov Disord. (2009) 24:1139-43. doi: 10.1002/mds.22491

56. Bello O, Sanchez JA, Lopez-Alonso V, Márquez G, Morenilla L, Castro $\mathrm{X}$, et al. The effects of treadmill or overground walking training program on gait in Parkinson's disease. Gait Posture. (2013) 38:590-5. doi: 10.1016/j.gaitpost.2013.02.005

57. Armstrong MJ, Okun MS. Diagnosis and treatment of parkinson disease: a review. JAMA. (2020) 323:548-60. doi: 10.1001/jama.2019.22360

58. Feng YS, Yang SD, Tan ZX, Wang MM, Xing Y, Dong F, et al. The benefits and mechanisms of exercise training for Parkinson's disease. Life Sci. (2020) 245:117345. doi: 10.1016/j.lfs.2020.117345

59. Bello O, Fernandez-Del-Olmo M. How does the treadmill affect gait in Parkinson's disease? Curr Aging Sci. (2012) 5:28-34. doi: 10.2174/1874609811205010028

60. Roeder L, Boonstra TW, Kerr GK. Corticomuscular control of walking in older people and people with Parkinson's disease. Sci Rep. (2020) 10:2980. doi: 10.1038/s41598-020-59810-w

61. Grabli D, Karachi C, Welter ML, Lau B, Hirsch EC, Vidailhet M, et al. Normal and pathological gait: what we learn from Parkinson's disease. J Neurol Neurosurg Psychiatr. (2012) 83:979-85. doi: 10.1136/jnnp-2012302263

62. Ford MP, Malone LA, Nyikos I, Yelisetty R, Bickel CS. Gait training with progressive external auditory cueing in persons with Parkinson's disease. Arch Phys Med Rehabil. (2010) 91:1255-61. doi: 10.1016/j.apmr.2010.04.012

63. de Bruin N, Doan JB, Turnbull G, Suchowersky O, Bonfield S, Hu B, et al. Walking with music is a safe and viable tool for gait training in Parkinson's disease: the effect of a 13-week feasibility study on single and dual task walking. Parkinson's Dis. (2010) 2010:483530. doi: 10.4061/2010/483530

64. Koshimori Y, Strafella AP, Valli M, Sharma V, Cho SS, Houle S, et al. Motor synchronization to Rhythmic Auditory Stimulation (RAS) attenuates dopaminergic responses in ventral striatum in young healthy adults: [ $\left.{ }^{11} \mathrm{C}\right]-(+)-$ PHNO pet study. Front Neurosci. (2019) 13:106. doi: $10.3389 /$ fnins.2019.00106

65. Nombela C, Hughes LE, Owen AM, Grahn JA. Into the groove: can rhythm influence Parkinson's disease? Neurosci Biobehav Rev. (2013) 37:2564-70. doi: 10.1016/j.neubiorev.2013.08.003

66. Kotz SA, Schwartze M. Differential input of the supplementary motor area to a dedicated temporal processing network: functional and clinical implications. Front Integr Neurosci. (2011) 5:86. doi: 10.3389/fnint.2011.00086

67. Schwartze M, Kotz SA. A dual-pathway neural architecture for specific temporal prediction. Neurosci Biobehav Rev. (2013) 37:2587-96. doi: 10.1016/j.neubiorev.2013.08.005

68. Crasta JE, Thaut MH, Anderson CW, Davies PL, Gavin WJ. Auditory priming improves neural synchronization in 
auditory-motor entrainment. Neuropsychologia. (2018) 117:102-12. doi: 10.1016/j.neuropsychologia.2018.05.017

69. Chung JW, Burciu RG, Ofori E, Coombes SA, Christou EA, Okun MS, et al. Beta-band oscillations in the supplementary motor cortex are modulated by levodopa and associated with functional activity in the basal ganglia. NeuroImage Clin. (2018) 19:559-71. doi: 10.1016/j.nicl.2018. 05.021

70. Ghai S, Ghai I, Schmitz G, Effenberg AO. Effect of rhythmic auditory cueing on parkinsonian gait: A systematic review and meta-analysis. Sci Rep. (2018) 8:506. doi: 10.1038/s41598-017-16232-5

71. Fischer $\mathrm{P}$, Chen CC, Chang YJ, Yeh CH, Pogosyan A, Herz $\mathrm{DM}$, et al. Alternating Modulation of Subthalamic Nucleus Beta Oscillations during Stepping. J Neurosci. (2018) 38:5111-21. doi: 10.1523/JNEUROSCI.3596-17.2018

72. Jenkinson $\mathrm{N}$, Brown P. New insights into the relationship between dopamine, beta oscillations and motor function. Trends Neurosci. (2011) 34:611-8. doi: 10.1016/j.tins.2011.09.003

73. Kadivar Z, Corcos DM, Foto J, Hondzinski JM. Effect of step training and rhythmic auditory stimulation on functional performance in Parkinson patients. Neurorehabil Neural Repair. (2011) 25:626-35. doi: 10.1177/1545968311401627

74. Meijer D, te Woerd E, Praamstra P. Timing of beta oscillatory synchronization and temporal prediction of upcoming stimuli. Neuroimage. (2016) 138:233-41. doi: 10.1016/j.neuroimage.2016.05.071

75. Hutchison WD, Dostrovsky JO, Walters JR, Courtemanche R, Boraud T, Goldberg J, et al. Neuronal oscillations in the basal ganglia and movement disorders: evidence from whole animal and human recordings. J Neurosci. 24:9240-3. doi: 10.1523/JNEUROSCI.3366-04.2004

76. Kühn AA, Kupsch A, Schneider GH, Brown P. Reduction in subthalamic $8-35 \mathrm{~Hz}$ oscillatory activity correlates with clinical improvement in Parkinson's disease. Eur J Neurosci. (2006) 23:1956-60. doi: $10.1111 / j .1460-9568.2006 .04717 . x$

77. Sharott A, Gulberti A, Zittel S, Tudor Jones AA, Fickel U, Munchau A, et al. (2014). Activity parameters of subthalamic nucleus neurons selectively predict motor symptom severity in Parkinson's disease. J Neurosci. 34:627385. doi: 10.1523/JNEUROSCI.1803-13.2014

78. Doyle LMF, Kühn AA, Hariz M, Kupsch A, Schneider GH, Brown P. Levodopa-induced modulation of subthalamic beta oscillations during selfpaced movements in patients with Parkinson's disease. Eur J Neurosci. (2005) 21:1403-12. doi: 10.1111/j.1460-9568.2005.03969.x

79. Cao CY, Zeng K, Li DY, Zhan SK, Li XL, Sun BM. Modulations on cortical oscillations by subthalamic deep brain stimulation in patients with Parkinson disease: a MEG study. Neurosci Lett. (2017) 636:95-100. doi: 10.1016/j.neulet.2016.11.009

80. Kibleur A, David O. Electroencephalographic read-outs of the modulation of cortical network activity by deep brain stimulation. Bioelectron Med. (2018) 4:2. doi: 10.1186/s42234-018-0003-x

81. Muthuraman M, Koirala N, Ciolac D, Pintea B, Glaser M, Groppa S, et al. Deep brain stimulation and L-DOPA therapy: concepts of action and clinical applications in Parkinson's disease. Front Neurol. (2018) 9:711. doi: 10.3389/fneur.2018.00711

82. Tan H, Zavala B, Pogosyan A, Ashkan K, Zrinzo L, Foltynie T, et al. Human subthalamic nucleus in movement error detection and its evaluation during visuomotor adaptation. J Neurosci. (2014) 34:16744-54. doi: 10.1523/JNEUROSCI.3414-14.2014

83. Tan H, Wade C, Brown P. Post-movement beta activity in sensorimotor cortex indexes confidence in the estimations from internal models. $J$ Neurosci. (2016) 36:1516-28. doi: 10.1523/JNEUROSCI.3204-15.2016

84. Feingold J, Gibson DJ, DePasquale B, Graybiel AM. Bursts of beta oscillation differentiate postperformance activity in the striatum and motor cortex of monkeys performing movement tasks. Proc Natl Acad Sci USA. (2015) 112:13687-92. doi: 10.1073/pnas.1517629112

85. Brittain JS, Brown P. Oscillations and the basal ganglia: motor control and beyond. Neuroimage. (2014) 85:637-47. doi: 10.1016/j.neuroimage.2013.05.084

86. Hell F, Plate A, Mehrkens JH, Botzel K. Subthalamic oscillatory activity and connectivity during gait in Parkinson's disease. Neuroimage Clin. (2018) 19:396-405. doi: 10.1016/j.nicl.2018.05.001
87. Oswal A, Brown P, Litvak V. Synchronized neural oscillations and the pathophysiology of Parkinson's disease. Curr Opin Neurol. (2013) 26:662-70. doi: 10.1097/WCO.0000000000000034

88. Quinn EJ, Blumenfeld Z, Velisar A, Koop MM, Shreve LA, Trager $\mathrm{MH}$, et al. Beta oscillations in freely moving Parkinson's subjects are attenuated during deep brain stimulation. Mov Disord. (2015) 30:1750-8. doi: $10.1002 / \mathrm{mds} .26376$

89. Spedden ME, Choi JT, Nielsen JB, Geertsen SS. Corticospinal control of normal and visually guided gait in healthy older and younger adults. Neurobiol Aging. (2019) 78:29-41. doi: 10.1016/j.neurobiolaging.2019.02.005

90. Storzer L, Butz M, Hirschmann J, Abbasi O, Gratkowski M, Saupe D, et al. Bicycling suppresses abnormal beta synchrony in the Parkinsonian basal ganglia. Ann Neurol. (2017) 82:592-601. doi: 10.1002/ana.25047

91. Arnal LH, Giraud A-L. Cortical oscillations and sensory predictions. Trends Cogn Sci. (2012) 16:390-8. doi: 10.1016/j.tics.2012.05.003

92. Saleh M, Reimer J, Penn R, Ojakangas CL, Hatsopoulos NG. Fast and slow oscillations in human primary motor cortex predict oncoming behaviorally relevant cues. Neuron. (2010) 65:461-71. doi: 10.1016/j.neuron.2010.02.001

93. Teki S. Beta drives brain beats. Front Syst Neurosci. (2014) 8:155. doi: $10.3389 /$ fnsys.2014.00155

94. Singh A. Oscillatory activity in the cortico-basal ganglia-thalamic neural circuits in Parkinson's disease. Eur J Neurosci. (2018) 48:2869-78. doi: 10.1111/ejn.13853

95. Androulidakis AG, Brücke C, Kempf F, Kupsch A, Aziz T, Ashkan K, et al. Amplitude modulation of oscillatory activity in the subthalamic nucleus during movement. Eur J Neurosci. (2008) 27:1277-84. doi: $10.1111 / j .1460-9568.2008 .06085 . x$

96. Joundi RA, Brittain JS, Green AL, Aziz TZ, Brown P, Jenkinson N. Persistent suppression of subthalamic beta-band activity during rhythmic finger tapping in Parkinson's disease. Clin Neurophysiol. (2013) 124:565-73. doi: $10.1016 /$ j.clinph.2012.07.029

97. Delval A, Bayot M, Defebvre L, Dujardin K. Cortical oscillations during gait: wouldn't walking be so automatic? Brain Sci. (2020) 10:90. doi: 10.3390/brainsci10020090

98. Rao SM, Mayer AR, Harrington DL. The evolution of brain activation during temporal processing. Nat Neurosci. (2001) 4:317-23. doi: 10.1038/85191

99. Canessa A, Pozzi NG, Arnulfo G, Brumberg J, Reich MM, Pezzoli G, et al. Striatal dopaminergic innervation regulates subthalamic beta-oscillations and cortical-subcortical coupling during movements: preliminary evidence in subjects with Parkinson's disease. Front Hum Neurosci. (2016) 10:611. doi: 10.3389/fnhum.2016.00611

100. Gaynor LM, Kühn AA, Dileone M, Litvak V, Eusebio A, Pogosyan $A$, et al. Suppression of beta oscillations in the subthalamic nucleus following cortical stimulation in humans. Eur J Neurosci. (2008) 28:1686-95. doi: $10.1111 / j .1460-9568.2008 .06363 . x$

101. Bartolo R, Prado L, Merchant H. Information processing in the primate basal ganglia during sensory-guided and internally driven rhythmic tapping. J Neurosci. (2014) 34:3910-23. doi: 10.1523/JNEUROSCI.2679-13.2014

102. Grahn JA. Neural mechanisms of rhythm perception: current findings and future perspectives. Top Cogn Sci. (2012) 4:585-606. doi: $10.1111 / j .1756-8765.2012 .01213 . x$

103. Hallett M, Di Iorio R, Rossini PM, Park JE, Chen R, Celnik P, et al. Contribution of transcranial magnetic stimulation to assessment of brain connectivity and networks. Clin Neurophysiol. (2017) 128:2125-39. doi: 10.1016/j.clinph.2017.08.007

104. Molnar GF, Sailer A, Gunraj CA, Cunic DI, Lang AE, Lozano AM, et al. Changes in cortical excitability with thalamic deep brain stimulation. Neurology. (2005) 64:1913-9. doi: 10.1212/01.WNL.0000163985.89444.DD

105. Ruge D, Cif L, Limousin P, Gonzalez V, Vasques X, Hariz MI, et al. Shaping reversibility? Long-term deep brain stimulation in dystonia: the relationship between effects on electrophysiology and clinical symptoms. Brain. (2011) 134(Pt. 7):2106-15. doi: 10.1093/brain/awr122

106. Ruge D, Tisch S, Hariz MI, Zrinzo L, Bhatia KP, Quinn NP, et al. Deep brain stimulation effects in dystonia: time course of electrophysiological changes in early treatment. Mov Disord. (2011) 26:1913-21. doi: 10.1002/mds. 23731

107. Kuriakose R, Saha U, Castillo G, Udupa K, Ni Z, Gunraj C, et al. The nature and time course of cortical activation following subthalamic 
stimulation in Parkinson's disease. Cerebral Cortex. (2010) 20:1926-36. doi: 10.1093/cercor/bhp269

108. Sailer A, Molnar GF, Paradiso G, Gunraj CA, Lang AE, Chen R. Short and long latency afferent inhibition in Parkinson's disease. Brain. (2003) 126:1883-94. doi: 10.1093/brain/awg183

109. Sailer A, Cunic DI, Paradiso GO, Gunraj CA, Wagle-Shukla A, Moro E, et al. Subthalamic nucleus stimulation modulates afferent inhibition in Parkinson disease. Neurology. (2007) 68:356-63. doi: 10.1212/01.wnl.0000252812.95774.aa

110. Morgante F, Espay AJ, Gunraj C, Lang AE, Chen R. Motor cortex plasticity in Parkinson's disease and levodopa-induced dyskinesias. Brain. (2006) 129:1059-69. doi: 10.1093/brain/awl031

111. Kim SJ, Udupa K, Ni Z, Moro E, Gunraj C, Mazzella F, et al. Effects of subthalamic nucleus stimulation on motor cortex plasticity in Parkinson disease. Neurology. (2015) 85:425-32. doi: 10.1212/WNL.0000000000001806

112. Naro A, Russo M, AbdelKader M, Manganotti P, Genovesi V, Marino $\mathrm{M}$, et al. A local signature of LTP-like plasticity induced by repetitive paired associative stimulation. Brain Topogr. (2015) 28:238-49. doi: 10.1007/s10548-014-0396-0

113. Udupa K, Bahl N, Ni Z, Gunraj C, Mazzella F, Moro E, et al. Cortical plasticity induction by pairing subthalamic nucleus deepbrain stimulation and primary motor cortical transcranial magnetic stimulation in Parkinson's disease. J Neurosci. (2016) 36:396-404. doi: 10.1523/JNEUROSCI.2499-15.2016

114. Ahlskog JE, Muenter MD, Maraganore DM, Matsumoto JY, Lieberman A, Wright KF, et al. Fluctuating Parkinson3s disease. Treatment with the longacting dopamine agonist cabergoline. Arch Neurol. (1994) 51:1236-41. doi: 10.1001/archneur.1994.00540240080020

115. Blin O. The pharmacokinetics of pergolide in Parkinson3s disease. Curr Opin Neurol. (2003) 16:S9-12. doi: 10.1097/00019052-200312001-00003

116. Sharott A, Gulberti A, Hamel W, Köppen JA, Münchau A, Buhmann C, et al. Spatio-temporal dynamics of cortical drive to human subthalamic nucleus neurons in Parkinson's disease. Neurobiol Dis. (2018) 112:49-62. doi: 10.1016/j.nbd.2018.01.001

117. Cheron G, Duvinage M, De Saedeleer C, Castermans T, Bengoetxea A, Petieau M, et al. From spinal central pattern generators to cortical network: integrated BCI for walking rehabilitation. Neural Plastic. (2012) 2012:375148. doi: $10.1155 / 2012 / 375148$
118. Temperli P, Ghika J, Villemure J-G, Burkhard PR, Bogousslavsky J, Vingerhoets FJG. How do parkinsonian signs return after discontinuation of subthalamic DBS? Neurology. (2003) 60:78-81. doi: 10.1212/WNL.60.1.78

119. Singh A, Plate A, Kammermeier S, Mehrkens JH, Ilmberger J, Bötzel K. Freezing of gait-related oscillatory activity in the human subthalamic nucleus. Basal Ganglia. (2013) 3:25-32. doi: 10.1016/j.baga.2012.10.002

120. Perera S, Patel KV, Rosano C, Rubin SM, Satterfield S, Harris T, et al. Gait speed predicts incident disability: a pooled analysis. J Gerontol Ser A Biol Sci Med Sci. (2016) 71:63-71. doi: 10.1093/gerona/glv126

121. Bötzel K, Kraft E. Strategies for treatment of gait and posture associated deficits in movement disorders: The impact of deep brain stimulation. Restor Neurol Neurosci. (2010) 28:115-22. doi: 10.3233/RNN-2010-0532

122. Logigian E, Hefter H, Reiners K, Freund HJ. Does tremor pace repetitive voluntary motor behavior in Parkinson's disease? Ann Neurol. (1991) 30:1729. doi: 10.1002/ana.410300208

123. Brown P, Marsden CD. Bradykinesia and impairment of EEG desynchronization in Parkinson's disease. Mov Disord. (1999) 14:423-9.

124. Pötter-Nerger M, Volkmann J. Deep brain stimulation for gait and postural symptoms in Parkinson's disease. Mov Disord. (2013) 28:1609-15. doi: $10.1002 / \mathrm{mds} .25677$

125. Freeman JS, Cody FW, Schady W. The influence of external timing cues upon the rhythm of voluntary movements in Parkinson3s disease. J Neurol Neurosurg Psychiatr. (1993) 56:1078-84. doi: 10.1136/jnnp.56.10.1078

126. Tanaka K, Quadros AC Jr, Santos RF, Stella F, Gobbi LT, Gobbi S. Benefits of physical exercise on executive functions in older people with Parkinson's disease. Brain Cogn. (2009) 69:435-41. doi: 10.1016/j.bandc.2008.09.008

Conflict of Interest: The authors declare that the research was conducted in the absence of any commercial or financial relationships that could be construed as a potential conflict of interest.

Copyright () 2020 Naro, Pignolo, Sorbera, Latella, Billeri, Manuli, Portaro, Bruschetta and Calabrò. This is an open-access article distributed under the terms of the Creative Commons Attribution License (CC BY). The use, distribution or reproduction in other forums is permitted, provided the original author(s) and the copyright owner(s) are credited and that the original publication in this journal is cited, in accordance with accepted academic practice. No use, distribution or reproduction is permitted which does not comply with these terms. 